\title{
Faceted Apophysis on Coracoid Process of Scapula in the Indian Population: Prevalence and Clinical Significance
}

\author{
Garima $\mathrm{S}^{1 *}$, Anita $\mathrm{R}^{2}$, Jyoti $\mathrm{C}^{2}$ and Navneet $\mathrm{K}^{3}$ \\ ${ }^{1}$ Assistant Professor, Department of Anatomy, K.G. Medical University, India \\ ${ }^{2}$ Professor, Department of Anatomy, K.G. Medical University, India \\ ${ }^{3}$ Professor \& Head, Department of Anatomy, K.G. Medical University, India
}

\section{Research Article}

Volume 2 Issue 3

Received Date: August 28, 2018

Published Date: October 03, 2018

*Corresponding author: Dr. Garima Sehgal, Assistant Professor, Department of Anatomy, K.G. Medical University, UP, Lucknow, India, 226003, Tel: 7376126434; Email: garimasehgal@kgmcindia.edu

\section{Abstract}

Coracoclavicular (CCJ) joint a diarthrodial synovial articulation sometimes exists between the conoid tubercle of clavicle \& superior surface of coracoid process. It presents with a variable frequency ranging between $0.55 \%$ and $30 \%$. This unique entity is usually asymptomatic but may sometimes present with pain or predispose to arthritic changes in neighbouring joints of shoulder region. The study was undertaken to find out the prevalence of this joint in Indian population from osteological samples and included 500 scapulae; 250 right and 250 of left side. Evidence of CCJ was obtained in the form of definitive facets on superior surface of coracoid process. Presence of facets for joint was observed in $21.8 \%$ with a higher proportion on left side (26\%) as compared to right (17.6\%). Facets presented with a spectra of shapes and surface features. CCJ is not rare and likely to have an acquired etiology favoured by genetic and environmental factors.

Keywords: Coracoclavicular Joint; Coracoid Process; Apophysis; Articular Facet; Shoulder; Osteology

\section{Introduction}

Movements at the shoulder are brought about by complex coordinated movements occurring at various joints of the shoulder region. Coracoclavicular region at the shoulder contains the coracoclavicular ligament attached between the posterior part of superior surface of coracoid process and the conoid tubercle and trapezoid line on the inferior surface of lateral $1 / 3$ of clavicle. Usually a bursa intervenes between the coracoid and the inferior surface of the clavicle between conoid and trapezoid parts. A diarthrodial synovial articulation may sometimes exist between the conoid tubercle of clavicle \& superior surface of coracoid process known as the coracoclavicular joint. It was first described in 1861 by Gruber, following which, there have been many reported cases identified on chest X-rays, dry skeletons or cadavers [1]. Its frequency according to osteological studies, dissection or radiological studies ranges between $0.55 \%$ and $30 \%[2,3]$. The existence of a coracoclavicular joint can be indicated by an articular facet on the conoid tubercle or on the craniomedial surface of the coracoid process [4]. Racial variations in the incidence of the coracoclavicular joint have been suggested and Cockshott (1979) [5] reported that the joint is more common in Asians than in Europeans or Africans, however, Nalla and 
Asvat (1995) [6] reported no significant racial differences in the incidence of this joint.

Some authors described that the joint probably developed more by genetics than by environmental factors or congenital abnormalities, while others suggested a developmental etiology, proposing, that the joint resulted from larger scapulae and longer clavicles coupling with a normal-sized thoracic inlet, which may restrict associated movements of the scapula $[4,6]$.

Several suggestions concerning the ontogeny of the coracoclavicular joint have been proposed. De Haas et al., 1965 described 1 large family in which the condition appeared to be inherited as an autosomal dominant trait [7].

Pillay (1967) [8] classified the joint according to its developmental stage as: grade I, fully developed joint with fibrocartilage lined articular surfaces and entire articular capsule, and grade II, a primitive or imperfect joint where the clavicle and the coracoid articulate with each other, and sometimes the facet is present only on the clavicle, without any cartilage covered articular surface or capsule.

It is important to recognize this so called unique variation as it may be associated with clinical symptoms in the form of shoulder pain and arthritis involving this joint itself or the adjacent sternoclavicular and acromioclavicular joints.

The present study was conducted to find out the presence of faceted apophysis on the coracoid process of scapulae in the Indian Population from random bone samples in the osteology laboratory, thus providing evidence, suggestive of the prevalence of a coracoclavicular joint in the Indian population.

\section{Material and Methods}

Material used in this study were 500 dried scapulae retrieved from cadavers of Indian origin and were collected from the Osteology laboratory of Department of Anatomy, King George's Medical University, Lucknow, U.P. The observations and analysis were done during a 6 month period from June 2017- November 2017. The posterior part of superior surface of coracoid process of scapula was observed for the presence of a definite articular facet to ascertain the presence of the coracoclavicular joint (Figure 1). Presence of the articular facet was recorded according to the side of scapula and facets were photographed by Sony DSC-W 35 digital camera. An attempt was made to give a morphologic description of the faceted apohysis wherein the surface projection and surface features of the faceted apophysis were also observed and categorized accordingly.

\section{Results}

Clearly demarcated articular facets for the coracoclavicular joint were present in 109 scapulae $(21.8 \%)$ out of 500 scapulae examined, and were observed in 44 scapulae of the right side (17.6\%) and 65 left scapulae (26\%) (Table 1). Articular facets presented with different shapes; oval, reniform, pyriform, round and irregular, they were grouped according to their shapes and the prevalence was calculated (Figure 2). The most common shape was reniform (59.6\%) followed by oval $(15.5 \%)$, pyriform $(14.6 \%)$, round $(5.5 \%)$ and irregular $(4.5 \%)$ (Table 2). Surface architecture of the facet was found to be either smooth $(70.6 \%)$ or rough $(29.4 \%)$ (Figure 3), articular surface was found to be projected in $76.2 \%$, whereas, it was flat in $23.8 \%$ (Figure 4 ) (Tables 3 \& 4). Articular surface was predominantly smooth on both sides $(70.6 \%)$, proportion wise there were more smooth facets on right as compared to left and rougher facets on left as compared to right (Table 3). Majority of facets were elevated on both sides (76.2\%), though elevated facets were proportionately larger on left side whereas flat facets were proportionatel; why higher on the right (Table 4). Prevalence of various types of facets was calculated according to surface elevation and surface architecture.

\begin{tabular}{|c|c|c|c|c|c|c|}
\hline & Right (n=250) & \% Prevalence & Left (n=250) & \% Prevalence & Total (n=500) & \% Prevalence \\
\hline Facets Absent & 206 & 82.4 & 185 & 74 & 391 & 78.2 \\
\hline Facets Present & 44 & 17.6 & 65 & 26 & 109 & 21.8 \\
\hline
\end{tabular}

Table 1: Prevalence of faceted apophysis on coracoid process.

\begin{tabular}{|c|c|c|c|c|c|c|}
\hline Shape of faceted & Right & Percentage & Left & Percentage & Total & Percentage \\
\hline apophysis & $\mathbf{( n = 2 5 0 )}$ & Prevalence (\%) & $\mathbf{( n = 2 5 0 )}$ & Prevalence (\%) & $\mathbf{( n = 5 0 0 )}$ & Prevalence (\%) \\
\hline Oval & 8 & 3.2 & 9 & 3.6 & 17 & 15.5 \\
\hline
\end{tabular}




\section{Journal of Human Anatomy}

\begin{tabular}{|c|c|c|c|c|c|c|}
\hline Reniform & 26 & 10.4 & 39 & 15.6 & 65 & 59.6 \\
\hline Pyriform & 4 & 1.6 & 12 & 4.8 & 16 & 14.6 \\
\hline Round & 5 & 2 & 1 & 0.4 & 6 & 5.5 \\
\hline Irregular & 1 & 0.4 & 4 & 1.6 & 5 & 4.5 \\
\hline TOTAL & $\mathbf{4 4}$ & $\mathbf{1 7 . 6}$ & $\mathbf{6 5}$ & $\mathbf{2 6}$ & $\mathbf{1 0 9}$ & $\mathbf{2 1 . 8}$ \\
\hline
\end{tabular}

Table 2: Shapes of articular facets on coracoid process and individual prevalence.

\begin{tabular}{|c|c|c|c|c|c|c|}
\hline $\begin{array}{c}\text { Surface architecture } \\
\text { of apophysis }\end{array}$ & $\begin{array}{c}\text { Right } \\
\text { (n=44) }\end{array}$ & $\begin{array}{c}\text { Percentage } \\
\text { Prevalence (\%) }\end{array}$ & $\begin{array}{c}\text { Left } \\
\text { (n=65) }\end{array}$ & $\begin{array}{c}\text { Percentage } \\
\text { Prevalence (\%) }\end{array}$ & $\begin{array}{c}\text { Total } \\
\text { (n=109) }\end{array}$ & $\begin{array}{c}\text { Percentage } \\
\text { Prevalence (\%) }\end{array}$ \\
\hline Smooth & 33 & 75 & 44 & 67.69 & 77 & $70.6 \%$ \\
\hline Rough & 11 & 25 & 21 & 32.31 & 32 & $29.4 \%$ \\
\hline
\end{tabular}

Table 3: Surface architecture of articular facets on coracoid process and prevalence.

\begin{tabular}{|c|c|c|c|c|c|c|}
\hline $\begin{array}{c}\text { Surface projection of } \\
\text { apophysis }\end{array}$ & $\begin{array}{c}\text { Right } \\
(\mathbf{n = 4 4 )}\end{array}$ & $\begin{array}{c}\text { Percentage } \\
\text { Prevalence (\%) }\end{array}$ & $\begin{array}{c}\text { Left } \\
(\mathbf{n = 6 5 )}\end{array}$ & $\begin{array}{c}\text { Percentage } \\
\text { Prevalence (\%) }\end{array}$ & $\begin{array}{c}\text { Total } \\
(\mathbf{n = 1 0 9 )}\end{array}$ & $\begin{array}{c}\text { Percentage } \\
\text { Prevalence (\%) }\end{array}$ \\
\hline Flat & 18 & 40.91 & 8 & 12.30 & 26 & $23.8 \%$ \\
\hline Elevated & 26 & 59.09 & 57 & 87.70 & 83 & $76.2 \%$ \\
\hline
\end{tabular}

Table 4: Surface projections of articular facets on coracoid process and prevalence.
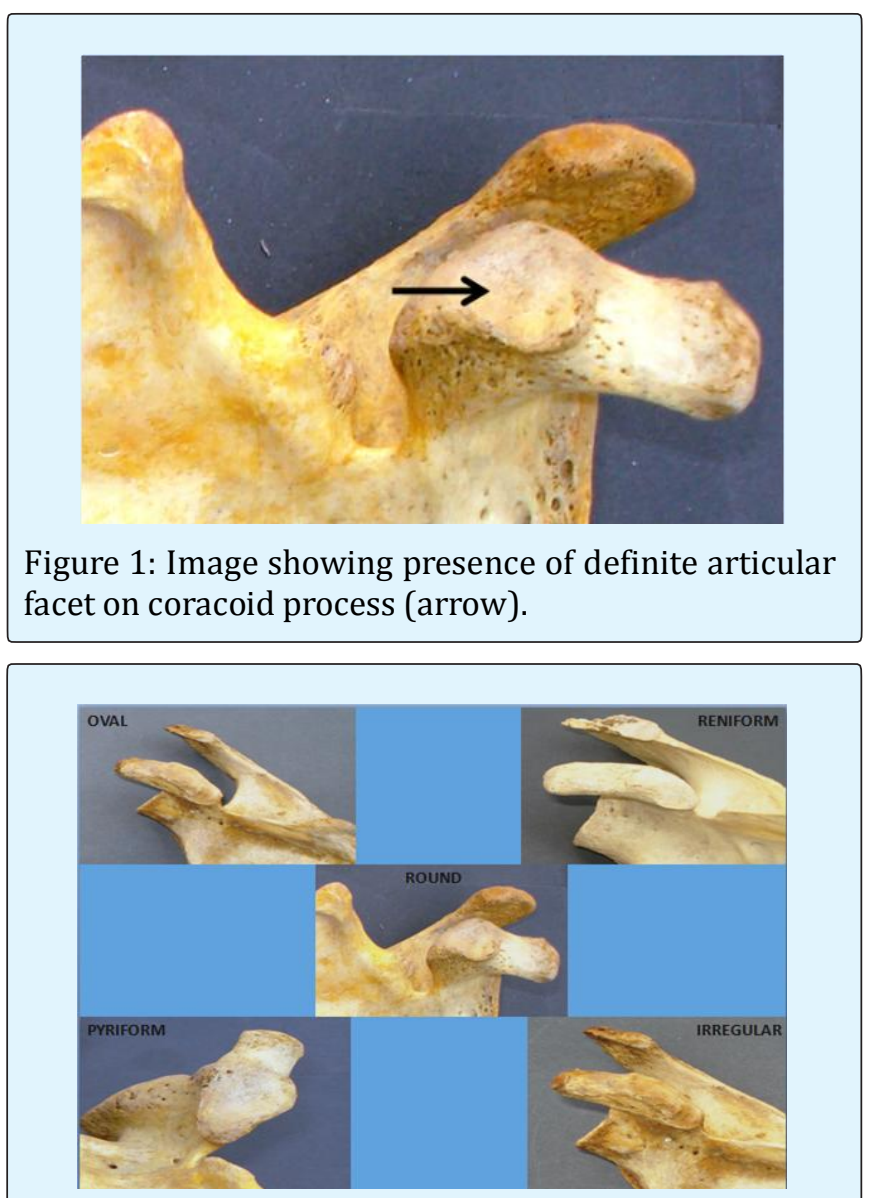

Figure 2: Image showing different shapes of faceted apophysis.

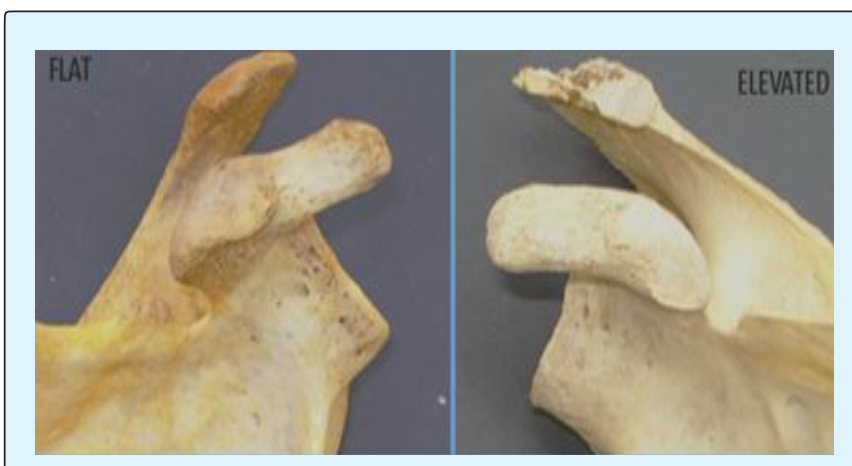

Figure 3: Image showing types of surface projection of articular facet.

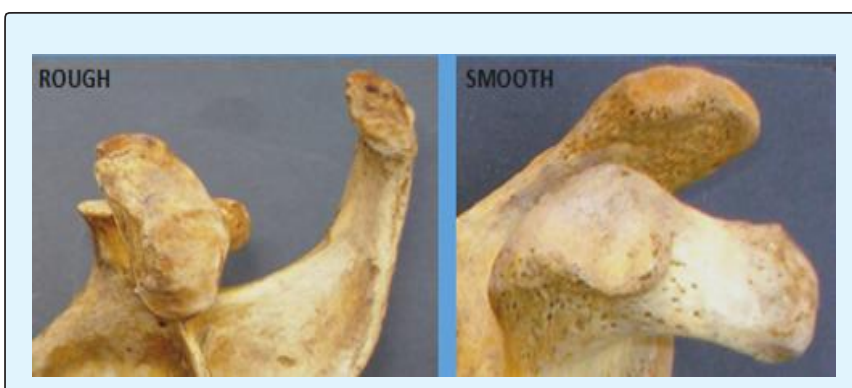

Figure 4: Image showing types of surface architecture of articular facet.

\section{Discussion}

Early years of studies on the human body have suggested the existence of the coracoclavicular joint $[1,9]$. 
Some early investigators considered coracoclavicular joint to be a rare anomaly $[10,11]$, but other authors came to the conclusion that the joint was not rare $[12,13]$. A considerable variation in the incidence of the coracoclavicular joint has thus been suggested by different authors. Among various population groups radiological studies report a lower prevalence [14], as compared to osteological (10\%) [6,15] and cadaveric studies (30\%) [12]. Studies from osteological material in a similar population group as ours, also reported a high prevalence of the joint 10\% [4], \& $16 \%$ [16], although it was less than the prevalence being reported in our study $(21.8 \%)$, whereas a radiological study in a similar population group reported a much lower prevalence (3.37\%) [17]. The occurrence of coracoclavicular joint can be recognized radiologically by the presence of an articular facet on a large bony prominence at the conoid tubercle, which is the radiological criterion for picking up this joint [8]. However, as highlighted by a previous study, quite well-formed articulations could exist without the presence of the prominent bony processes, and a bony process could exist without an articular facet [4]. Since the identification of the joint depends on these, it could be responsible for differences in prevalence observed by different studies. The prevalence of joint was higher on left side in our study, in confirmation to findings of other authors [6,17], and it has been reported by many that unilateral occurrence of joint is more common than bilateral, however few studies reported bilateral occurrence as common one $[3,18]$.

Geographical variations exist and studies have suggested that CCJ is more commonly seen in Asians than in Africans or Europeans with a prevalence of nearly $10 \%$ (range 0.5-20\%) with an equal male: female distribution $[6,18]$. Osteological studies conducted in India report 5.6-16\% prevalence of CCJ. We found a much higher prevalence of CCJ in our study (21.8\%), and our findings substantiated and reconfirmed both the above facts; firstly, our study was osteological and secondly, it included samples from cadavers of Asian origin (Indian). A higher prevalence of CCJ as in our study has also been reported by Pillay (1967) [8] in 150 cases of mixed Asian origin. Lack of significant sexual difference in the incidence of this joint have been reported in white South Africans, whereas other investigators reported that the joint was more common in males than in females [6]. We did not address the gender related differences in prevalence in our osteological study.

It has been described that during embryonic life coracoid process is connected with clavicle by cartilaginous procoracoid which transforms into coracoclavicular ligament. The conoid tubercle, which is usually in form of small rough surface elevation, may occasionally grow out in the direction of coracoid process. The coracoid process may also react by forming a similar outgrowth. The two processes can then form real joint. In case of formation of joint, two processes are covered by cartilage and are surrounded by a capsule and lined by synovium.

CCJ is a normal morphological trait in gorillas and gibbons [8]. Existence of this joint in humans was reported much later in the latter half of nineteenth century. There is a huge controversy among authors regarding what predisposes or causes the development of CCJ in humans. Factors that induce the development of the coracoclavicular joint in humans are therefore unclear. Lane (1888) [19] thought that this joint was an acquired joint favoured by a particular occupation but the study by Kaur and Jit (1991) [4] in 1991 refuted his theory by concluding that there was no relation between the existence of the joint and any particular occupation. Gowland (1915) [20] and Lewis (1959) [13] proposed the congenital etiology which was again challenged by Kaur and Jit (1991) [4], who argued against a congenital origin as they were unable to find an articular facet of this joint in fetuses, neonates, or children under 13 years of age. They also proposed that formation of the joint later in life was probably caused more by genetics than by environmental factors.

Nalla and Asvat (1995) [6] observed that individuals possessing a coracoclavicular joint showed a significantly longer first rib, longer scapula border lengths (medial, lateral and cranial), longer paracostal lengths and greater cranial angles of the scapula. They thought that movement of the scapulae might be restricted in individuals with the joint, and this could be due to the longer and narrower scapulae, coupled with a normal thoracic inlet size. From these observations they concluded that the coracoclavicular joint may develop in individuals having these features.

On the basis of heterogenecity of the articular facets uniquely observed and reported in our study with an array of shapes, surface features and varied surface projections, we would like to propose an acquired etiology. We would also like to second the earlier opinion of various authors that formation of the joint later in life could be additionally influenced by certain genetic and environmental factors. As we did not measure any of the involved or neighbouring bones, we are unable to comment on the likelihood of CCJ presence and 
association with varied dimensions of first rib scapular borders and angles, and coracoid process.

Presence of CCJ has been reportedly found to be accountable for humeral head fracture [21] and also associated with decrease in movement of the upper limb [11]. It is not universally agreed that the coracoclavicular joint undergoes arthritic changes, though Kier, et al. (1986) [22] reported that the presence of this joint does predispose to degenerative changes involving the sternoclavicular joint and acromioclavicular joints [22], while some authors also suggest that the joint itself has a tendency to undergo arthritis changes [2].

\section{Conclusion}

During the course of our study we observed the presence of facets for CCJ in $21.8 \%$, and would therefore like to propose that the coracoclvicular joint is not rare, but rather, a common variant of the pectoral girdle. The facets displayed distinctive shapes with unique surface features and surface projection. On the basis of these variations in the morphology of the articular surfaces we would like to suggest an acquired etiology in the formation of these joints. Presence of this joint may affect motion in the upper limb or could be responsible for, paresthesias and/or brachialgia.

Our observations related to surface projection and surface features on the joint facet are unique and could lay down the foundation for newer static or dynamic imaging studies or peroperative studies at the shoulder to trace the etiology of this so called rare and clinically insignificant anomaly.

\section{References}

1. Gruber WL (1861) A monograph with remarks including: contributions to the anatomy of the region infraclavicularis and deltoidea. Mem Acad Sci St Petersbourg VII Series 3: 1-28.

2. Gumina S, Salvatore M, De Santis P, Orsina L, Postachini F (2002) Coracoclavicular joint : osteologic study of 1020 human clavicles. J Anat 201(6): 513519.

3. Olotu JE, Oladipo GS, Eroje MA, Edipamode IE (2008) Incidence of coracoclavicular joint in adult Nigerian population. Scientific Res Essay 3(4): 165-167.

4. Kaur H, Jit I (1991) Brief communication: Coracoclavicular joint in Northwest Indians. Ame J
Phy Anthrop 85(4): 457-460.

5. Cockshott WP (1979) The coracoclavicular joint. AJR 131: 313-316.

6. Nalla S, Asvat $R$ (1995) Incidence of the coracoclavicular joint in South African populations. J Anat 186(3): 645-649.

7. De Haas WHD, Kingma MJ, Drucker DF (1965) The coracoclavicular joint and related pathological conditions. Ann Rheum Dis 24: 257-266.

8. Pillay VK (1967) The coraco-clavicular joint. Singapore Med J Sep 8(3): 207-213.

9. Meyer AW (1915) Anatomical specimens of unusual clinical interest. Am J Othop Surg 13(1): 86-89.

10. Wertheimer LG (1948) Coracoclavicular joint: Surgical treatment of painful syndrome caused by anomalous joint. J Bone Joint Surg 30(3): 570-578.

11. Hall FJS (1950) Coracoclavicular joint: a rare condition treated successfully by operation. Br Med J 1(4656): 766-768.

12. Poirier $P$ (1890) La claviculeetses articulations. J Anat Physiol 26: 81-103.

13. Lewis OJ (1959) The coracoclavicular joint. J Anat 93: 296-303.

14. Fischer LP, Vuillard JF, Blanc A, Bouchet (1971) L'articulation coracoclaviculaire. Lyon Med 225: 1257-1260.

15. Cho BP, Kang HS (1998) Articular facets of the coracoclavicular joint in Koreans. Acta Anat 163(1): 56-62.

16. Kaul N (2016) An evaluation of prevalence of coracolclavicular joint in humans by osteological and radiological studies in Delhi and NCR. Med Res Chron 3(3): 250-261.

17. Chopra J, Rani A, Bajpai PK, Manik P (2017) Prevalence of Coracoclavicular Joint In Northern India: Radiological Evidence. J Clinic Diag Res 11(11): AC01AC04.

18. Nehme A, Tricoire JL, Giordano G, Rouge D, Chiron P, et al. (2004) Coracoclavicular joints. Reflections upon incidence, pathophysiology and etiology of the different forms. Surg Radiol Anat 26(1): 33-38. 
19. Lane WA (1888) The anatomy and physiology of the shoemaker. J Anat 22(4): 593-628.

20. Gowland WP (1915) Preliminary note on a diarthrodial articulation between the clavicle and the coracoid. J Anat Physiol 49(4): 187-189.

21. Frasseto F (1921) Trecasi di articulazione coraco- clavicolare osservate radiograficamente sul vivente. Chir Org Mov (5): 116-124.

22. Kier R, Wain SL, Apple J, Martinez S (1986) Osteoarthritis of the sternoclavicular joint. Radiographic features and pathologic correlation. Invest Radiol 21(3): 227-223.

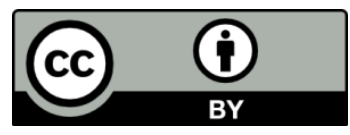

